\title{
Efectos de la aplicación de micorrizas vesículo arbuscular nativa (MVA) sobre las condiciones físicas y químicas de suelos con vocación minera
}

\section{Effects of applying arbuscular mycorrhizal vesicular native (MVA) on the physical and chemical soil conditions with mining vocation}

\author{
Moisés Mosquera-Blandón1, Viky Yenci Vega-Hurtado²
}

Resumen

Mediante el seguimiento de parcelas experimentales, utilizando como planta hospedera a maíz chococito inoculada con micorrizas vesículo arbuscular (MVA) nativas de la especie Glomus sp., se evalúo sus efectos sobre las condiciones edáficas en un suelo del municipio de Tadó. Se utilizó un diseño estadístico de bloques al azar, dos tratamientos (0 y $250 \mathrm{~g} /$ planta), tres repeticiones. Se realizó análisis físicoquimico de suelos antes del establecimiento y después de la cosecha del maíz. Finalmente, se determinó la relación de la MVA nativa y los cambios en las condiciones físicas y químicas del suelo cultivado. Los resultados de las muestras analizadas en laboratorio determinaron cambios en $\mathrm{pH}$, contenidos de materia orgánica, $\mathrm{P}, \mathrm{K}, \mathrm{Al}^{+3}$, Ca y Mg, pero no en las condiciones físicas de dicho suelo. Los datos más significativos se obtuvieron en la concentración final de P, que se incrementó en 733\% con respecto al valor inicial de 3 ppm, asimismo se registró un aumento de 155,5\% en Ca y $150 \%$ en $\mathrm{Mg}$.

Palabras clave: Edáfico, Fósforo, Inoculación, Glomus sp., MVA.
1 Ingeniero agrónomo, especialista en $\mathrm{Ge}$ rencia de Recursos Naturales, Magister en Liderazgo y Gerencia Ambiental, Investigador Principal del Componente Productivo, Instituto de Investigaciones Ambientales del Pacífico(IIAP), Quibdó, Colombia.

e-mail:mmosquera@iiap.org.co

2 Ingeniera agroforestal. Contratista Instituto de Investigaciones Ambientales del Pacífico (IIAP), Quibdó, Colombia.e-mail:vikyyenci15@hotmail.com

Recibido: 15 de febrero de 2012

Aceptado: 30 abril de 2012

\begin{abstract}
By tracking plots, using corn chococito host plant inoculated with VA mycorrhizal native g. Glomus sp, was evaluated their effects on soil conditions in soil Tadó Township. Statistical design was a randomized block, two treatments (0 and 250 $\mathrm{g} /$ plant), three repetitions. We performed physical - chemical analysis of soils before and after establishment of the corn harvest. Finally, we investigated the relationship of native MVA and changes in physical and chemical conditions of the cultivated soil. The results of the samples analyzed in the laboratory determined changes in $\mathrm{pH}$, organic matter content, $\mathrm{P} \mathrm{K}, \mathrm{Al}^{+3}$, Ca and $\mathrm{Mg}$, but not so in the physical conditions of the soil. The most significant data were obtained at the final concentration of $P$, which increased by $733 \%$ over the initial value of 3 ppm, also, there was an increase of $155.5 \%$ in Ca and $150 \%$ $M g$.
\end{abstract}

Keywords: Edaphic, Glomus sp., Inoculation, Phosphorus, MVA.

\section{Introducción}

Los suelos en el departamento del Chocó, presentan deficiencia de nutrientes, lo que redunda en la poca fertilidad de los mismos, ocasionados entre otros factores por la excesiva precipitación (rango entre 8000 a 12000 mm/año) generando procesos de lixiviación y alta acidez, lo que se constituye en una limitante para el desarrollo vegetativo y productivo de los cultivos, porque las plantas no encuentran la cantidad necesaria de elementos nutrientes disponibles para su normal crecimiento (Malagón, 2002).

El auge de la minería en la década de 1980 en el municipio 
de Tadó generó un proceso de deterioro físico, químico, biológico y social en los recursos naturales de la región, por la influencia directa e indirecta de esta actividad. Dentro de estos recursos, el suelo ha pasado a ser uno de los más deficientes e improductivos para la población. Se estima que existen aproximadamente unas 10.000 hectáreas deterioradas por la explotación del oro de aluvión, tierras sin ningún uso agropecuario (CODECHOCO 2000). Estos terrenos no están siendo utilizados para ninguna actividad por la alta destrucción del perfil del suelo donde la fertilidad se ha perdido por completo.

Estudios adelantados por el Instituto de Investigaciones Ambientales del Pacífico (IIAP) en las estaciones ambientales de Tutunendo y Tadó han demostrado que cuando se ha aplicado $250 \mathrm{~g}$ de MVA nativa del género Glomus a maíz chococito, pasto brachiaria de cumbens, frutales nativos en vivero, especies aromáticas en azoteas, es la dosis de mayor eficacia y eficiencia bajo las condiciones agroambientales de la región.

El objetivo principal de este estudio fue determinar los cambios en las condiciones físicas y químicas por la aplicación de $250 \mathrm{~g}$ de MVA en suelos disturbados por actividad minera en el área de influencia de la Estación Ambiental del Alto San Juan (EAASJ), como estrategia eficaz que conduzca a la recuperación e incorporación de estas áreas al sistema productivo regional.
Área de estudio. La EAASJ se encuentra localizada en el corregimiento de Playa de Oro y sus zonas de influencia, aproximadamente a unos 30 min por la vía que va desde Tadó a Pereira. La EAASJ cubre en términos locales, el área de influencia del Consejo Comunitario Mayor de Comunidades Negras de ASOCASAN, pertenecientes al municipio de Tadó, departamento del Chocó, República de Colombia (Plan de Ordenamiento Territorial del Municipio de Tadó, IIAP, 2006). La Figura 1 muestra la localización del área de estudio dentro de la Estación Ambiental del Alto San Juan del IIAP.

La cuenca alta del río San Juan la conforman los municipios de Tadó en el departamento del Chocó y Pueblo Rico en el departamento de Risaralda. El municipio de Tadó está ubicado en la parte oriental del departamento del Chocó, dentro de la zona del Alto San Juan, con un área aproximada de $878 \mathrm{~km}^{2}$; su cabecera municipal está ubicada a los $76^{\circ} 73^{\prime} 10^{\prime \prime}$ de longitud occidental, al margen izquierdo del río San Juan y a la derecha del río Mungarrá y a $66 \mathrm{~km}$ de la ciudad de Quibdó y 549 km de Bogotá (Plan de Desarrollo Municipal de Tadó, 2007-2011).

\section{Método}

Durante el desarrollo de este estudio se llevaron a cabo cuatro (4) fases experimentales:

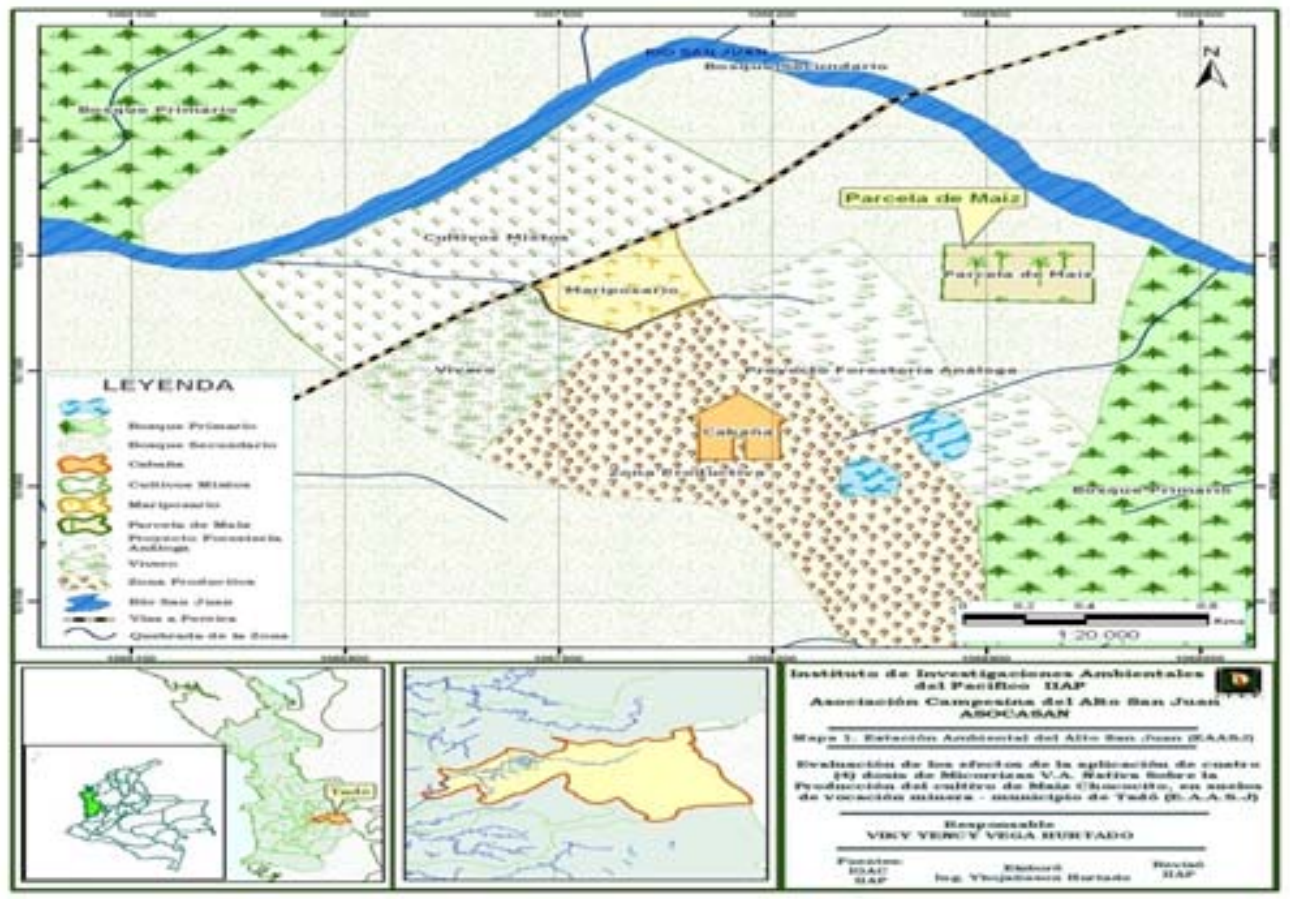

Figura 1. Localización de la Estación Ambiental Alto San J uan

Fuente: Plan de Ordenamiento Territorial del Municipio de Tadó, IIAP.2006 
Fase 1. Determinación del área de estudio y toma de muestra de suelo

La EAASJ se ubica en el corregimiento de Playa de Oro, zona en donde ancestralmente las comunidades han desarrollado la actividad minera, es por ello, que el sitio escogido correspondió a un área que había sido trabajado con minería y que se encontraba por más de dos años en proceso de recuperación natural.

En esta fase se tomó la primera muestra de suelo $(1 \mathrm{~kg}) \mathrm{de}$ la rizósfera de la planta, a una profundidad entre $0-20 \mathrm{~cm}, \mathrm{y}$ se envió al laboratorio para la realización de su respectivo análisis físico químico. En el análisis se determinaron entre otros, los siguientes parámetros: $\mathrm{pH}, \mathrm{MO}$, bases intercambiables, textura, CIC, $\mathrm{Ca}, \mathrm{Mg}, \mathrm{K}, \mathrm{P}$.

Considerando la homogeneidad del lote, el procedimiento para la toma de muestras antes de la siembra y después de la cosecha, consistió en recorrer en zigzag el área de estudio siguiendo dos líneas diagonales en forma de $\mathrm{X}$ donde se escogieron los sitios de muestreo en forma sistemática tomando una submuestra en cada uno de ellos, a una profundidad de $20 \mathrm{~cm}$, en un balde limpio, se homogeneizaron y retiraron elementos como piedras, raíces, etc. Posteriormente, se secó la muestra a la sombra evitando su contaminación con otros elementos, se pesaron y empacaron $500 \mathrm{~g}$ de suelo en una bolsa de papel kraf y se rotularon los datos necesarios para la identificación de las muestras (Figura 2).

Para determinar los cambios físicos y químicos en el suelo se enviaron las muestras a los laboratorios de suelos certificados pertenecientes a las universidades Tecnológica de Pereira y Nacional sede Medellín, para adelantar los respectivos análisis de fertilidad antes de la siembra y después de la cosecha del maíz chococito.

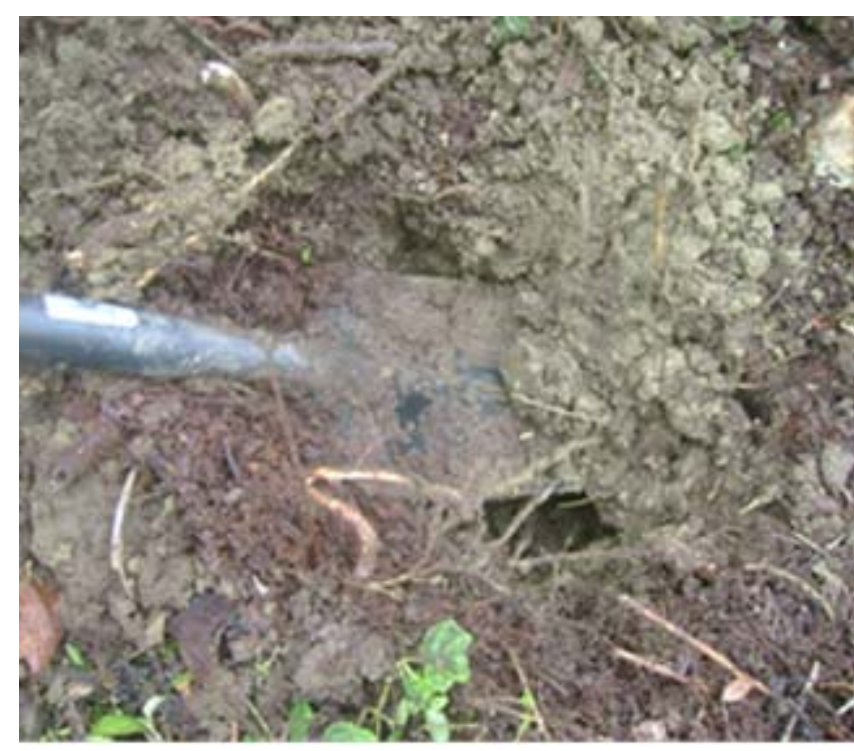

Figura 2. Primera muestra de suelo

\section{Fase 2. Inoculación de plántulas de maíz chococito}

A partir de inóculo de la especie Glomus sp. producido en el banco de germoplasma de micorrizas del IIAP en Tutunendo, se inocularon a nivel de vivero las plántulas de maíz chococito. Para ello, se prepararon bolsas de 16 × 16 $\mathrm{cm}$, llenas con un sustrato compuesto por arena lavada, bojeo y hojarasca en proporción 3:1:1; con la ayuda de una vareta de madera se hizo un orificio en cada una de ellas en cuyo fondo se aplicó la dosis de $250 \mathrm{~g} /$ planta de micorrizas y luego la posterior siembra de las plántulas en bolsas de almacigo, garantizando el contacto entre las raíces de las plántulas y el inóculo aplicado (Figura 3).

\section{Fase 3. Establecimiento de parcelas}

Posterior a la adecuación del terreno escogido se realizó la siembra de plántulas en sitio definitivo, se establecieron 6 parcelas distribuidas en bloques al azar, cada parcela tuvo un área de $6 \mathrm{~m}^{2}$, con una distancia de siembra entre plantas de 1 $\mathrm{m}$ x $1 \mathrm{~m}$, para una densidad de 12 plántulas por parcela. Se hicieron hoyos de $20 \mathrm{~cm}$ de profundidad, donde se depositaron al azar tanto las plántulas testigos y aquellas inoculadas con todo el material contenido en las bolsas de almacigo provenientes del vivero.

Cosechado el cultivo de maíz chococito, se procedió a la toma inmediata de la segunda muestra de suelo $(1 \mathrm{~kg})$ de la rizósfera de la planta, a una profundidad entre 0 y $20 \mathrm{~cm}$, luego se envió al laboratorio para la realización de su respectivo análisis físico químico.

Diseño experimental. El ensayo se desarrolló bajo condiciones de campo, con un diseño experimental de bloques completamente al azar. Se evaluaron cepas de hongos micorrícicos del género Glomus sp. y el testigo. Para la incorporación de la MVA al suelo, se inocularon plantas de maíz chococito. Se establecieron dos tratamientos 0 y $250 \mathrm{~g} /$ planta de inóculo de micorrizas, con tres repeticiones cada

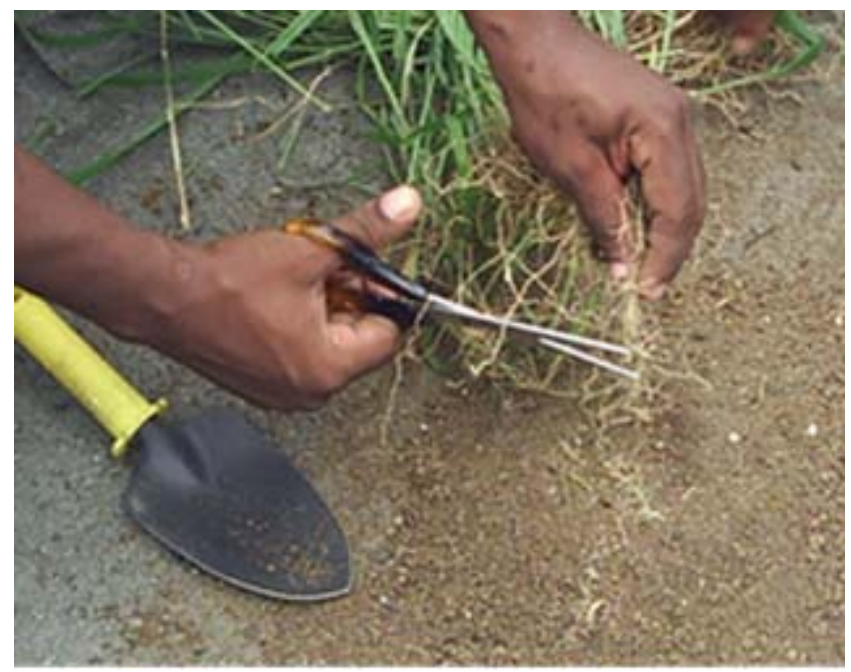

Figura 3. Preparación inoculo micorrizas 
uno, para un total de seis unidades experimentales, todas bajo las mismas condiciones agroambientales (temperatura, humedad relativa, precipitación y horas luz/sol).

Las variables evaluadas fueron los cambios en las condiciones físicas y químicas en el suelo cultivado, para lo cual se tomaron y analizaron muestras de suelos antes del establecimiento de las parcelas experimentales en campo e inmediatamente después de la cosecha del maíz. Se aplicó un análisis estadístico o análisis de varianza univariado (ANDEVA) y el análisis de varianza multivariado. Las hipótesis propuestas fueron:

Hipótesis 0. La incorporación de hongos MVA en suelos disturbados por minería, en proceso de descanso natural causa efectos benéficos en su condición física y química.

Hipótesis 1. La incorporación de hongos MVA en suelos disturbados por minería, en proceso de descanso natural no causa efectos benéficos en su condición física y química.

\section{Resultados y discusión}

Los resultados muestran que los análisis físicos químicos realizados antes de la siembra y posterior a la cosecha de maíz, revelan que no hubo cambios en las condiciones físicas del suelo porque en ambos casos se mantuvo la textura franco arenosa (FA) determinada inicialmente.

Efectos sobre las condiciones físicas del suelo. Con respecto a las características físicas, los resultados muestran que los análisis realizados antes de la siembra y posterior a la cosecha de maíz, que no hubo cambios en las condiciones físicas del suelo porque en ambos casos se mantuvo la textura FA determinada inicialmente (Tabla 1).

Efectos sobre las condiciones químicas del suelo. Los análisis muestran cambios a nivel de la acidez del suelo, porque a pesar de que se mantuvo la concentración del aluminio intercambiable $(2.6 \mathrm{cmolc} \mathrm{kg}-1)$, el $\mathrm{pH}$ varió de 4.6-4.2, acentuando su condición de suelo muy ácido, esto se explica porque de acuerdo con Rodríguez y Fraga (1999), Tarafdar y Marschner (1995) y Halder (1990) y Mishra (1990), la solubilización del fósforo mineral es un proceso fundamentalmente relacionado con la producción y liberación de ácidos orgánicos por parte de algunos microorganismos como bacterias y hongos asociados con la raíz de la planta, es así, que distintos ácidos orgánicos tales como el ácido oxálico, malónico, succínico y el glucónico han sido identificados y relacionados con estos microorganismos solubilizadores de P. La liberación de estos ácidos a la rizósfera de la planta provoca la acidificación del suelo y esto puede directamente incrementar la solubilización del fósforo (Tabla 1).

Asimismo, Cuenca et al. (2001) consideran que aun cuando la tolerancia de las micorrizas a la acidez y los altos niveles de aluminio es un tema controversial, en suelos ácidos tropicales tipo ultisol estos factores no parecen afectar el desempeño de las micorrizas arbusculares nativas, inclusive pudiendo el hongo acumular aluminio en su micelio, vesículas y células auxiliares.

La disminución de la materia orgánica está asociada con el aprovechamiento y/o con la alta demanda que la especie Zea maiz requiere para desarrollar sus procesos metabólicos en las fases de crecimiento vegetativo y la producción final de mazorcas.

De acuerdo con Azcón-Aguilar (1983) y Kucey et al. (1989), la asociación de micorrizas con Rhizobium, bacterias gran negativas y otros microorganismos habitantes de la rizósfera, con capacidad de movilizar a través de la solubilización elementos poco abundantes como el fósforo, mejora la disponibilidad de nutrientes en la solución del suelo, explicando que los análisis realizados al suelo muestren en relación con las bases intercambiables, un aumento significativo en la concentración del $\mathrm{Ca}$ y $\mathrm{Mg}$, así como una leve disminución en la concentración del K.

Bathia et al. (1996), Janos (1983), Sieverding (1984),

Tabla 1

Efectos de la aplicación de micorrizas vesículo arbuscular nativa (MVA) sobre las condiciones físico-químicas de suelos con vocación minera

\begin{tabular}{llcccccccc}
\hline $\begin{array}{c}\text { Tratamientos } \\
\text { (g/ planta) }\end{array}$ & \multicolumn{1}{c}{ Muestras } & $\begin{array}{c}\text { Profundidad } \\
\mathbf{c m}\end{array}$ & Textura & $\mathbf{p H}$ & $\mathbf{M O} \%$ & $\mathbf{A l}$ & $\mathbf{C a} \mathbf{M g}$ & $\mathbf{K}$ & $\begin{array}{c}\mathbf{P} \\
\mathbf{p p m}\end{array}$ \\
\hline 0 & $\begin{array}{l}\text { Análisis } \\
\text { (antes de la siembra) }\end{array}$ & 20 & FA & 4.6 & 16.5 & 2.6 & 0.9 & 0.20 .18 & 3 \\
250 & 20 & FA & 4.2 & 11.1 & 2.6 & 1.4 & 0.30 .10 & 22 \\
\hline 250 & $\begin{array}{l}\text { Análisis } \\
\text { (después de la cosecha) }\end{array}$ & & & & & & & & \\
\hline
\end{tabular}

Fuente: Instituto de Investigaciones Ambientales 


\section{Bioetnia Volumen 9 № 2 (julio-diciembre), 2012}

citados por Arcos et al. (2007), consideran que factores como la acidez y la concentración de materia orgánica, fósforo, nitrógeno, aluminio, cobre y zinc en el suelo, inciden sobre el buen establecimiento y desempeño de la simbiosis con micorrizas, lo cual se refleja en la capacidad de colonización de hospederos y la producción de esporas de los hongos.

El efecto más relevante se evidenció en el aumento muy significativo de la concentración del $\mathrm{P}$ en la muestra final de suelo ya que este tuvo un incremento de $733,3 \%$ (19 ppm), lo cual es explicable por la actividad de las micorrizas en la rizósfera de la planta, lo que revalida lo dicho por Dodd et al. (1996). Hay quienes afirman que una alternativa de manejo para mejorar el estado nutricional de los suelos es el uso de mecanismos biológicos que permitan restituir su fertilidad, sin perturbar y/o empeorar su condición. Entre estos mecanismos se podrían nombrar las asociaciones simbióticas como las MVA especializadas en la captación de fósforo de la solución del suelo (Tabla 1).

Asimismo, en el cultivo de maíz, el P es absorbido, mayormente en las primeras etapas del ciclo del cultivo, lo cual podría también explicar la alta concentración de este elemento en la solución del suelo al momento de la cosecha.

De acuerdo con Dodd y Sylvia (1999), nombrados por Toro, Bazó y López (2008), bajos contenidos de P en el suelo como lo es el caso de los suelos de Tadó y en general del Chocó favorecen el establecimiento de los hongos formadores de MVA a partir de la aplicación de micorrizas nativas como biofertilizantes, lo que genera un aumento en el contenido de fósforo disponible en la solución del suelo. Es de considerar además de que a $\mathrm{Ph}$ bajos aumenta la solubilidad del $\mathrm{P}$ en el suelo, lo cual se evidencia cuando observamos la variación de este factor en las muestras analizadas.

\section{Conclusiones}

Los resultados obtenidos en este estudio permiten concluir que el establecimiento en suelos con vocación minera de plantas de maíz chococito inoculadas con micorrizas vesículo arbuscular nativa del género Glomus sp. en dosis de $250 \mathrm{~g} /$ planta provoca de manera general, un marcado incremento en la concentración de elementos nutrientes en suelos con vocación minera, mejorando significativamente su fertilidad, lo cual presupone una condición benéfica que podría utilizarse en procesos de restauración de ecosistemas y recuperación de suelos disturbados por la actividad minera, así como la incorporación a mediano plazo de estas áreas en la dinámica agroproductiva regional.

La presencia de micorrizas en los suelos, moviliza una gran cantidad de nutrientes que antes no estaban a disposición de las plantas, por lo que incrementa la fertilidad de estos.

Considerando a las micorrizas como microorganismos regeneradores de suelos degradados, su utilización eficaz conduce al mejoramiento de la estructura de este, se incrementan sus posibilidades de retención de humedad, aireación y descomposición de la materia orgánica.

En concordancia con lo anterior, el inusitado incremento en la concentración de $\mathrm{P}$ (23 ppm), es decir 733,3\%, así como $155,5 \%$ de Ca y $150 \%$ de $\mathrm{Mg}$, revalida el importantísimo papel ecológico y ambiental que juegan las MVA, en los suelos del trópico húmedo que se caracterizan por su alta acidez, bajo contenido de elementos nutrientes y en general una baja fertilidad, lo que limita profundamente el desarrollo de actividades productivas asociadas con la soberanía alimentaria y restringe el crecimiento económico de las comunidades ancestrales asentadas en estas zonas.

\section{Recomendaciones}

Adelantar estudios que permitan evaluar otros efectos en el suelo relacionados con la interacción de micorrizas nativas con la microfauna de la rizósfera (nemátodos, afidios, ácaros, entre otros) de plantas de importancia económica y alimentaria a nivel local.

Evaluar sus efectos sobre la capacidad productiva en suelos poco productivos, como los afectados por la erosión hídrica y actividad minera en el Chocó.

- Determinar su potencial y uso en procesos de reforestación de cuencas y microcuencas de importancia regional afectadas por la actividad antrópica.

\section{Literatura citada}

Azcon-Aguilar, C. 1983. Interactions between phosphate solubilizing bacteria and VA mycorrhiza to improve plant to utilization of rock phosphate in nonacidic soils. $3^{\text {rd }}$ International Congress on Phosphorus Compounds. Brussels, 4-6 Oct. pp. 127-44.

Arcos A.L, J. H. Argüelles, G. I. Cardona, C. P. Peña-Venegas. 2007. Micorrizas arbusculares del sur de la amazonia colombiana y su relación con algunos factores fisicoquímicos y biológicos del suelo. Acta Amaz. 37 (3): 327 36.

Corporación para el Desarrollo Sostenible del Chocó, CODECHOCO. 2000. Control ambiental a la actividad minera en el departamento del Chocó. Quibdó: CODECHOCO.6 pp.

Cuenca, G., Z. De Andrade, E. Meneses. 2001. The presence of aluminum in arbuscular mycorrhizas of Clusia multiflora exposed to increased acidity. Plant Soil. 231: 233-41.

Dodd J.C., S. Rosendahl, M. Giovannetti, A. Broome, L. Lanfranco, C. Walker. 1996. Inter- and intraspecific variation within the morphologicallysimilar arbuscular mycorrhizal fungi Glomus mosseae and Glomus coronatum. New Phytol. 133: 113-22.

Halder, A. K., A. K. Mishra, P. Bhattacharyya, P. K. Chakrabartty. 1990. Solubilization of rock phosphate by Rhizobium and Bradirizobium. J Gen Appl Microbiol. 36: 81-92.

Janos, D. P. 1996. Mycorrhizas, succession, and the rehabilitation of deforested lands in the humid tropics. In: J. C. Frankland, N. Magan, G. M. Gadd (eds). Fungi and enviromental change. p. 129-62.

Kucey, R., H. Janzen, M. Leggett. 1989. Microbially mediated increases in plant available phosphorus. Adv Agron. 42: 199-225.

Malagón-Castro, D. 2002. Ensayo sobre la tipología de suelos colombianos, énfasis en génesis y aspectos ambientales. Rev Acad Colomb Cien. 27(104): 310-41. 
Micorrizas vésico arbuscular nativa y suelos con vocación minera. M. Mosquera-Blandón, VY. Vega-Hurtado

Plan de Ordenamiento Territorial del Municipio de Tadó. 2006. Quibdó: Instituto de Investigaciones Ambientales del Pacífico (IIAP).

Rodríguez, H., R. Fraga. 1999. Phosphate solubilizing bacteria and their role in plant growth promotion. Biotechnol Adv. 17: 319-39.

Sieverding, E. 1984. Importancia de las micorrizas en la nutrición de las plantas. I Curso Nacional de Micorrizas. Palmira: Facultad de Ciencias Agropecuarias. Proyecto Micorrizas CIAT. 1-6 pp.
Tarafdar, J. C., H. Marschner. 1995. Dual inoculation with Azospirillum fumigatus and Glomus mossae enhances biomass production and nutrient uptake in wheat (Triticum aestivum L) supplied with organic phosphorus as Na-phytate. Plant Soil. 173: 97-102.

Toro, M., I. Bazo, M. López. 2008. Micorrizas arbusculares y bacterias. En línea. [fecha de acceso: 10 de julio de 2012]. Disponible en URL: www.scielo.org.ve/scielo.php 